Pacific Journal of Mathematics

SINGULAR PERTURBATIONS OF DIFfERENTIAL EQUATIONS
IN ABSTRACT SPACES 


\title{
SINGULAR PERTURBATIONS OF DIFFERENTIAL EQUATIONS IN ABSTRACT SPACES
}

\author{
HUSSAIN S. NUR
}

In a recent paper, Kisynski studied the solutions of the abstract Cauchy problem $\varepsilon x \cdot(t)+x \cdot(t)+A x(t)=0, x(0)=x_{0}$ and $x(0)=x_{1}$ where $0 \leqq t \leqq T, \varepsilon>0$ is small parameter and $A$ is a nonnegative self-adjoint operator in a Hilbert space $H$. With the aid of the functional calculus of the operator $A$, he has showed that as $\varepsilon \rightarrow 0$ the solution of this problem converges to the solution of the unperturbed Cauchy problem $x(t)+A x(t)=0, x(0)=x_{0}$. Smoller has proved the same result for equation of higher order.

The purpose of this paper is to study the solution of a similar problem and allowing the operator $A$ to depend on $t$.

To be precise, we shall show that if the initial data is taken from a suitable dense subset of $H$, then the solution of the Cauchy problem:

$$
\varepsilon x^{\bullet} \cdot(t)+x \cdot(t)+A(t) x(t)=0, x(0)=x_{0}, x \cdot(0)=x_{1}
$$

converges to the solution of the unperturbed Cauchy problem

$$
x \cdot(t)+A(t) x(t)=0, x(0)=x_{0}
$$

as $\varepsilon \rightarrow 0$ where $0 \leqq t \leqq T, \varepsilon>0$ is a small parameter, $A(t)$ is a continuous semi-group of nonnegative self-adjoint operators in $H$ with infinitesimal generator $A$.

2. The problem (1.1) when $H=R_{1}$. Before considering (1.1) in the general case, it is necessary to consider (1.1) in the case when $H=R_{1}$ (i.e., the real line). Thus we consider the Cauchy problem:

$$
\varepsilon u \cdot(t)+u \cdot(t)+e^{\mu t} u(t)=0 . \quad u(0)=x_{0}, u \cdot(0)=x_{1}
$$

when $t \geqq 0, \mu \geqq 0 . \varepsilon>0$.

According to theorem (1) in [2], equation (2.1) has two linearly independent solutions:

$$
\begin{array}{ll}
u_{1}=\sum_{0}^{m-1} u_{1 \jmath}(t) \varepsilon^{j}+\varepsilon^{m} E_{0}, & u_{\mathrm{i}}=\sum_{0}^{m-1} u_{i j}(t) \varepsilon^{j}+\varepsilon^{m-1} E_{1} \\
u_{2}=\sum_{0}^{m-1} u_{2 j}(t) \varepsilon^{j} e^{-t / \varepsilon}+\varepsilon^{m} E_{0}, & u_{\mathrm{i}}=\sum_{0}^{m-1}(d / d t)\left[u_{2 j}(t) e^{-t \varepsilon}\right] \varepsilon^{j}+\varepsilon^{m-1} E_{1}
\end{array}
$$


where $u_{i j}(t)(i=1,2)$ are $C^{\infty}$ functions on $[0, T]$ and $u_{i 0}(t)(i=1,2)$ does not vanish at any point of $[0, T]$ and $E_{0}, E_{1}$ are functions of $\varepsilon$ and others, but bounded for small $\varepsilon \geqq 0$.

Hence the general solution of equation (2.1) is $u=c_{1} u_{1}+c_{2} u_{2}$. Solving for $c_{1}$ and $c_{2}$ by using the initial condition we obtain $u=$ $x_{0} s_{00}+x_{1} s_{01}$ and $u^{\cdot}=x_{0} s_{10}+x_{1} s_{11}$ where

$$
\begin{aligned}
& s_{00}=H^{-1}(\varepsilon)\left[u_{i}(0) u_{1}(t)-u_{i}(0) u_{2}(t)\right] \\
& s_{01}=H^{-1}(\varepsilon)\left[u_{1}(0) u_{2}(t)-u_{2}(0) u_{1}(t)\right] \\
& s_{10}=s_{00}=\frac{d}{d t} s_{00} \\
& s_{11}=s_{01}=\frac{d}{d t} s_{01}
\end{aligned}
$$

and

$$
H(\varepsilon)=u_{1}(0) u_{2}(0)-u_{2}(0) u_{i}(0)
$$

How taking the limit as $\varepsilon \rightarrow 0$, we find that

$$
\begin{aligned}
& s_{00}(t, \varepsilon, \mu) \longrightarrow x_{0} u_{10}(t) \\
& s_{01}(t, \varepsilon, \mu) \longrightarrow 0 .
\end{aligned}
$$

Consequently, $u(t, \varepsilon) \rightarrow x_{0} u_{10}(t)$. From equation 15 in [2] we find that $u_{10}(t)$ is the solution of the equation

$$
u+e^{\prime \prime t} u=0
$$

and this is what we wished to show.

3. Estimates for the Functions $s_{i j}(t, \varepsilon, \mu)$. In this section we would like to find estimates for the functions $s_{i j}(t, \varepsilon, \mu)(i, j=0,1)$. We may do so by solving for $u_{i j}(t)(i=1,2 ; j=0,1, \cdots, m-1)$ from equation 15 in [2]. Since this would be rather tedious we will take the simpler approach of estimating $u_{i}(t, \varepsilon, \mu)$ and $u_{i}(t, \varepsilon, \mu)$ $(i=1,2)$. Multiplying (2.1) by $u$ and integrating between 0 and $t$ we obtain:

$$
\frac{\varepsilon u^{\circ 2}}{2}+\int_{0}^{t} u^{\cdot 2}+\frac{u^{2}}{2} e^{\mu t}-\frac{1}{2} \mu \int_{0}^{t} u^{2} e^{\mu t}=c
$$

Consequently

$$
u^{2} \leqq 2|c|+\mu \int_{0}^{t} u^{2} e^{\mu t} d t
$$

Now using Bellman's lemma, we obtain 


$$
u^{2} \leqq 2 / c / e^{e^{\mu t}} .
$$

For estimating $u^{\bullet}(t)$, we multiply equation (2.1) by $e^{-\mu t} u^{\cdot}$, integrating between 0 and $t$ and using Bellman's lemma we obtain:

$$
u^{\cdot 2}(t) \leqq 2 \varepsilon^{-1} / c / e^{2 \mu t} .
$$

In [2] page 323 we proved that for all small $\varepsilon \geqq 0 H(\varepsilon) \neq 0$, therefore we see that (2.3), (3.1), and (3.2) yield,

$$
\left|s_{00}\right| \leqq K(\varepsilon) \exp \left(\frac{e^{\mu t}}{2}\right)
$$

$K(\varepsilon)$ is a bounded function in $\varepsilon$, and

$$
\left|s_{01}\right| \leqq \bar{K}(\varepsilon) \exp \left(e^{e^{\mu t} / 2}\right)
$$

$\bar{K}(\varepsilon)$ is a bounded function in $\varepsilon$.

To obtain an estimate for $s_{i j}(i, j=1,2)$ we write equation (2.1) in amatrix form as:

$$
U \cdot=A U
$$

when

$$
A=\left(\begin{array}{cc}
0 & 1 \\
-\bar{\varepsilon}^{1} \exp (\mu t) & -\bar{\varepsilon}^{1}
\end{array}\right) \text {. }
$$

Hence

$$
U=\exp \left[\int A(s) d s\right]=\left(\begin{array}{ll}
s_{00} & s_{01} \\
s_{10} & s_{11}
\end{array}\right)
$$

and from the equation

$$
\begin{aligned}
& (d / d t)\left(\begin{array}{ll}
s_{00} & s_{01} \\
s_{10} & s_{11}
\end{array}\right)=\left(\begin{array}{ll}
s_{00} & s_{01} \\
s_{10} & s_{11}
\end{array}\right)\left(\begin{array}{cc}
0 & 1 \\
-\bar{\varepsilon}^{1} \exp (\mu t) & -\bar{\varepsilon}^{1}
\end{array}\right) \\
& =\left(\begin{array}{cc}
0 & 1 \\
-\bar{\varepsilon}^{1} \exp (\mu t) & -\bar{\varepsilon}^{1}
\end{array}\right)\left(\begin{array}{ll}
s_{00} & s_{01} \\
s_{10} & s_{11}
\end{array}\right)
\end{aligned}
$$

we obtain

$$
\begin{aligned}
& s_{10}=-s_{01} \varepsilon^{-1} \exp (\mu t) \\
& s_{11}=s_{00}-\varepsilon^{-1} s_{01} .
\end{aligned}
$$

4. The problem (1.1) in abstract Hilbert space. We shall now consider the problem (1.1) in any Hilbert space $H$ with norm $\|\cdot\|$. 
Since $\{A(t)\}$ is a semi-group of a nonnegative selfadjoint operator in $H$, with infinitesimal generator $A$, there is a resolution of the identity $E_{k}$ such that $A(t)$ has the spectral representation:

$$
A(t)=\int_{0}^{\infty} e^{\prime t} d E_{\prime^{\prime \prime}} .
$$

We shall next use the functional calculus of the operator $A(t)$. For fixed $\varepsilon>0, t \geqq 0$, we define the operator $S_{i j}$ on $H$ by

$$
S_{i j}(t, \varepsilon)=\int_{0}^{\infty} s_{i j}(t, \varepsilon, \mu) d E_{\mu} \quad(i, j=0,1)
$$

where the $s_{i j}(t, \varepsilon, \mu)$ are defined by (2.3). If we let $D$ denote the dense domain of the operator $e^{A^{2}(t)}$ for all $t$, then our estimates (3.2) through (3.7) imply that $D$ is contained in the domain of $S_{i j}(t, \varepsilon)$ for every $i, j=0,1$.

For $x_{0}$ and $x_{1}$ in $D$, we write

$$
x_{\varepsilon}(t)=S_{00}(t, \varepsilon) x_{0}+S_{01}(t, \varepsilon) x_{1}
$$

and we see that $x_{\varepsilon}(t)$ is in the domain of $A(t)$ for every $\varepsilon>0$. We now state the main theorem.

THEOREm. Let $x_{\varepsilon}(t)$ be defined as in (4.2) when $x_{0}, x_{1}$ are in D. Then $x_{\varepsilon}(t)$ is the unique solution of the Cauchy problem (1.1) and $x_{\varepsilon}(t)$ converges to the solution of (1.2) as $\varepsilon \rightarrow 0$.

To prove this theorem we first prove the following lemmas:

LemMa 1. For $x \in D,(d / d t) S_{i j}(t, \varepsilon) x$ exists and

$$
(d / d t) S_{i j}(t, \varepsilon) x=\int_{0}^{\infty}(d / d t) s_{i \jmath}(t, \varepsilon, \mu) d E_{r, x} \quad(i, j=0,1) .
$$

Proof. We shall prove the lemma for $i=j=0$. Since the proofs for the other cases are similar, they will be omitted. For $x \in D$ and $t \geqq 0$ fixed, we have:

$$
\begin{aligned}
& \left\|\frac{S_{00}(t+\Delta t, \varepsilon)-S_{00}(t)}{\Delta t} \times-S_{10}(t, \varepsilon) x\right\|^{2} \\
= & \int_{0}^{\infty}\left[\frac{s_{00}(t+\Delta t, \varepsilon, \mu)-s_{00}(t, \varepsilon, \mu)}{\Delta t}-s_{10}(t, \varepsilon, \mu)\right]^{2} d \| E_{l, x \|^{2}} \\
= & \int_{0}^{\infty}\left[s_{10}\left(t^{\prime}, \varepsilon, \mu\right)-s_{10}(t . \varepsilon \cdot \mu)\right]^{2} d\left\|E_{r, x}\right\|^{2},
\end{aligned}
$$

where $t \leqq t^{\prime} \leqq t+\Delta t$, using the theorem of the mean and (2.3). 
Now there is a $T$ such that $t+\Delta t \leqq T$ for all $\Delta t$ sufficiently small, so that if we use (3.3) through (3.7) we see that

$$
\begin{aligned}
\left|s_{10}\left(t^{\prime}, \varepsilon, \mu\right)-s_{10}(t, \varepsilon, \mu)\right| & \leqq\left|s_{10}\left(t^{\prime}, \varepsilon, \mu\right)\right|+\left|s_{10}(t, \varepsilon, \mu)\right| \\
& \leqq \varepsilon^{-1} e^{\mu T} K(\varepsilon) e^{(1 / 2) e^{\mu T}} \leqq N(\varepsilon, T) e^{e^{\mu T}}
\end{aligned}
$$

where $N(\varepsilon, T)$ is a constant depending on $T$ and $\varepsilon$ only. Therefore the function $\left|s_{10}\left(t^{\prime}, \varepsilon, \mu\right)-s_{10}(t, \varepsilon, \mu)\right|^{2}$ is summable with respect to the measure $d\left\|E_{\mu} x\right\|^{2}$ if $\Delta t$ is sufficiently small. Furthermore,

$$
\lim _{A t \rightarrow 0}\left[s_{10}\left(t^{\prime}, \varepsilon, \mu\right)-s_{11}(t, \varepsilon, \mu)\right]^{2}=0 .
$$

So that the Lebseque dominated convergence theorem yields:

$$
\lim _{A t \rightarrow 0} \int_{0}^{\infty}\left[s_{10}\left(t^{\prime}, \varepsilon, \mu\right)-s_{10}(t, \varepsilon, \mu)\right]^{2} d\left\|E_{\mu} x\right\|^{2}=0 .
$$

This completes the proof of the lemma.

Lemma 2. For $x \in D$ and $t \geqq 0$, we have

$$
\begin{aligned}
& \lim _{\varepsilon \rightarrow 0}\left\|S_{00}(t, \varepsilon) x-\exp \left(-\int A(s) d s\right) x\right\|=0 \\
& \lim _{\varepsilon \rightarrow 0}\left\|S_{01}(t, \varepsilon) x\right\|=0 .
\end{aligned}
$$

Proof.

$$
\begin{aligned}
& \left\|S_{00}(t, \varepsilon) x-\exp \left(-\int A(s) d s\right) \times\right\|^{2} \\
= & \int_{0}^{\infty}\left|\left(s_{00}(t, \varepsilon, \mu)-\exp \left(-\int^{t} e^{\mu s} d s\right)\right)\right|^{2} d\left\|E_{\mu} x\right\|^{2} .
\end{aligned}
$$

From (3.3) we see that $\left[s_{00}(t, \varepsilon, \mu)-\exp \left(-\int^{t} e^{\mu s} d s\right)\right]^{2}$ is summable with respect to the measure $d\left\|E_{\mu} x\right\|^{2}$ and, as we have seen in (2.4) and (2.5), the integrand converges pointwise to zero. We apply the Lebesgue dominated convergence theorem to conclude that the integral likewise converges to zero as $\varepsilon \rightarrow 0$. This proves (4.4). Relation (4.5) follows from (2.4) and (2.5) likewise.

LEMmA 3. Let $B$ be a bounded operator in $H$. If $x \cdot(t)+B x(t)=0$, $0 \leqq t \leqq 0$, and $x(0)=0$, then $x(t) \equiv 0$.

The proof of the above lemma is in [3] and therefore will be omitted.

The proof of the theorem. That $x_{\varepsilon}(t)$ defined by (4.2) is a solu- 
tion of (1.1) follows at once from Lemma 1 by direct verification. The uniqueness of $x_{\varepsilon}(t)$ follows from Lemma 3 just as in [1]. Finally, since $\exp \left(-\int^{t} A(s) d s\right) x_{0}$ is the solution of (1.2) Lemma 2 shows that.

$$
\lim _{\varepsilon \rightarrow 0}\left\|x_{\varepsilon}(t)-\exp \left(-\int^{t} A(s) d s\right) x_{0}\right\|=0 .
$$

This completes the proof of the theorem.

\section{REFERENCES}

1. J. Kisynski, Sur les Equations Hyperboliques avec Petit Parametre, Colloq. Math.,. 10 (1963), 331-343.

2. Hussain S. Nur, Singular perturbation of linear partial differential equations,

J. Differential Equations 6 (1969), 1-12.

3. J. A. Smoller, Singular perturbation and a theorem of Kisynski, J. Math. Anal. Appl., 12, No. 1, (1965).

Received December 2, 1969.

Fresno State College 


\title{
PACIFIC JOURNAL OF MATHEMATICS
}

\section{EDITORS}

H. SAMELSON

Stanford University

Stanford, California 94305

C. R. HobвY

University of Washington

Seattle, Washington 98105

\section{J. DugunduI}

Department of Mathematics

University of Southern California

Los Angeles, California 90007

RICHARD ARENS

University of California

Los Angeles, California 90024

\section{ASSOCIATE EDITORS}
E. F. BECKENBACH
B. H. Neumann
F. WOLE
K. Yoshida

\section{SUPPORTING INSTITUTIONS}

\author{
UNIVERSITY OF BRITISH COLUMBIA \\ CALIFORNIA INSTITUTE OF TECHNOLOGY \\ UNIVERSITY OF CALIFORNIA \\ MONTANA STATE UNIVERSITY \\ UNIVERSITY OF NEVADA \\ NEW MEXICO STATE UNIVERSITY \\ OREGON STATE UNIVERSITY \\ UNIVERSITY OF OREGON \\ OSAKA UNIVERSITY \\ UNIVERSITY OF SOUTHERN CALIFORNIA
}

\author{
STANFORD UNIVERSITY \\ UNIVERSITY OF TOKYO \\ UNIVERSITY OF UTAH \\ WASHINGTON STATE UNIVERSITY \\ UNIVERSITY OF WASHINGTON

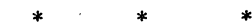 \\ AMERICAN MATHEMATICAL SOCIETY \\ CHEVRON RESEARCH CORPORATION \\ NAVAL WEAPONS CENTER
}

The Supporting Institutions listed above contribute to the cost of publication of this Journal, but they are not owners or publishers and have no responsibility for its content or policies.

Mathematical papers intended for publication in the Pacific Journal of Mathematics should be in typed form or offset-reproduced, (not dittoed), double spaced with large margins. Underline Greek letters in red, German in green, and script in blue. The first paragraph or two must be capable of being used separately as a synopsis of the entire paper. The editorial "we" must not be used in the synopsis, and items of the bibliography should not be cited there unless absolutely necessary, in which case they must be identified by author and Journal, rather than by item number. Manuscripts, in duplicate if possible, may be sent to any one of the four editors. Please classify according to the scheme of Math. Rev. Index to Vol. 39. All other communications to the editors should be addressed to the managing editor, Richard Arens, University of California, Los Angeles, California, 90024.

50 reprints are provided free for each article; additional copies may be obtained at cost in multiples of 50 .

The Pacific Journal of Mathematics is published monthly. Effective with Volume 16 the price per volume (3 numbers) is $\$ 8.00$; single issues, $\$ 3.00$. Special price for current issues to individual faculty members of supporting institutions and to individual members of the American Mathematical Society: $\$ 4.00$ per volume; single issues $\$ 1.50$. Back numbers are available.

Subscriptions, orders for back numbers, and changes of address should be sent to Pacific Journal of Mathematics, 103 Highland Boulevard, Berkeley, California, 94708.

PUBLISHED BY PACIFIC JOURNAL OF MATHEMATICS, A NON-PROFIT CORPORATION

Printed at Kokusai Bunken Insatsusha (International Academic Printing Co., Ltd.), 7-17, Fujimi 2-chome, Chiyoda-ku, Tokyo, Japan. 


\section{Pacific Journal of Mathematics}

\section{Vol. 36, No. $3 \quad$ BadMonth, 1971}

E. M. Alfsen and B. Hirsberg, On dominated extensions in linear subspaces of

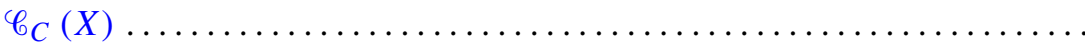

Joby Milo Anthony, Topologies for quotient fields of commutative integral

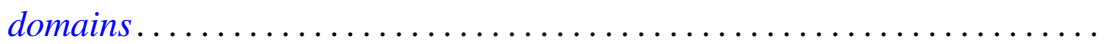

V. Balakrishnan, G. Sankaranarayanan and C. Suyambulingom, Ordered cycle lengths in a random permutation .......................... 603

Victor Allen Belfi, Nontangential homotopy equivalences............... 615

Jane Maxwell Day, Compact semigroups with square roots .............. 623

Norman Henry Eggert, Jr., Quasi regular groups of finite commutative nilpotent algebras .......................................... 631

Paul Erdős and Ernst Gabor Straus, Some number theoretic results ......... 635

George Rudolph Gordh, Jr., Monotone decompositions of irreducible Hausdorff continua .............................................

Darald Joe Hartfiel, The matrix equation $A X B=X \ldots \ldots \ldots \ldots \ldots \ldots . \ldots 69$

James Howard Hedlund, Expansive automorphisms of Banach spaces. II . . . . 671

I. Martin (Irving) Isaacs, The p-parts of character degrees in p-solvable

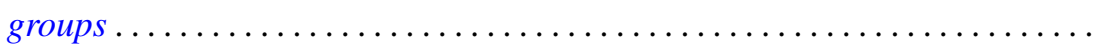

Donald Glen Johnson, Rings of quotients of $\Phi$-algebras ............... 693

Norman Lloyd Johnson, Transition planes constructed from semifield planes....

Anne Bramble Searle Koehler, Quasi-projective and quasi-injective modules.

James J. Kuzmanovich, Completions of Dedekind prime rings as second endomorphism rings...

B. T. Y. Kwee, On generalized translated quasi-Cesàro summability ...

Yves A. Lequain, Differential simplicity and complete integral closure

741

Mordechai Lewin, On nonnegative matrices.

753

Kevin Mor McCrimmon, Speciality of quadratic Jordan algebras ...

Hussain Sayid Nur, Singular perturbations of differential equations in abstract spaces .....................................

D. K. Oates, A non-compact Krein-Milman theorem .

Lavon Barry Page, Operators that commute with a unilateral shift on an invariant subspace...

Helga Schirmer, Properties of fixed point sets on dendrites.

Saharon Shelah, On the number of non-almost isomorphic models of $T$ in a

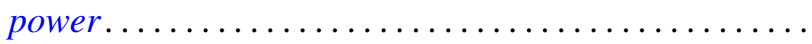

Robert Moffatt Stephenson Jr., Minimal first countable Hausdorff spaces....

Masamichi Takesaki, The quotient algebra of a finite von Neumann algebra 